PRÁTICAS EDUCATIVAS, MEMÓRIAS E ORALIDADES

Rev. Pemo - Revista do PEMO

\title{
Tutoria e identidade docente na educação a distância
}

\author{
Antonio Cavalcante Filho \\ Faculdade de Desenvolvimento das Américas, Fortaleza, CE, Brasil \\ Viviani Maria Barbosa Sales i \\ Faculdade de Desenvolvimento das Américas, Fortaleza, CE, Brasil \\ Francione Charapa Alves iii \\ Universidade Federal do Cariri, Brejo Santo, CE, Brasil
}

\begin{abstract}
Resumo
O presente texto traz uma reflexão sobre a diversidade de papéis que o professor assume na Educação a Distância, destacando a figura do tutor. Tem como objetivo discutir sobre a identidade docente no exercício da tutoria em Educação a Distância. Trata-se de uma investigação teórica fundamentada nas leituras de Alves, Simão e Leitinho (2018), Mororó (2017), Bego (2016), Belloni(2006), Gonzalez (2005), Mattar (2012), Bentes (2009). Também realizamos uma pesquisa documental com base em editais de seleção de tutores de três instituições públicas de Fortaleza que mantêm convênio dom a Universidade Aberta do Brasil. As leituras realizadas mostram que os autores divergem quanto ao fato do tutor ser considerado professor ou não. Entretanto, a maioria considera que o papel do tutor vai além do repasse de conteúdos, ele exerce inúmeras atribuições docentes, devendo, portanto, ser considerado professor- tutor.
\end{abstract}

Palavras-chave Tutor. Educação a distância. Identidade docente.

\section{Tutoring and teaching identity in distance education}

\begin{abstract}
This text reflects on the diversity of roles that the teacher assumes in Distance Education, highlighting the figure of the tutor. It aims to discuss the teaching identity in the exercise of tutoring in Distance Education. I t aims to discuss the teaching identity in the exercise of tutoring in Distance Education. This is a theoretical investigation based on the readings of Alves, Simão and Leitinho (2018), Mororó (2017), Bego (2016), Belloni (2006), Gonzalez (2005), Mattar (2012), Bentes (2009). We also conducted a documentary research based on calls for tutor selection from three public institutions in Fortaleza that maintain an agreement with the Open University of Brazil. The readings performed show that the authors differ as to whether the tutor is considered a teacher or not. However, most consider that the role of the tutor goes beyond the transfer of content, he has numerous teaching duties, and should therefore be considered a teacher-tutor.
\end{abstract}

Keywords: Tutor. Distance education. Teaching identity.

Rev. Pemo, Fortaleza, v. 2, n. 1, p. 1-15, 2020

DOI: https://doi.org/10.47149/pemo.v2i1.3632

https://revistas.uece.br/index.php/revpemo

ISSN: 2675-519X

Esta obra está licenciada com uma Licença Creative Commons

Atribuição 4.0 Internacional. 


\section{Introdução}

Hoje, ainda nos deparamos com uma demanda constante por educação, que tenciona mudanças nas escolas e universidades no que se refere à sua função e estrutura. Nesse contexto, é indiscutível o papel cada vez mais significativo que as tecnologias assumem no processo de socialização dos indivíduos nas sociedades modernas. No intuito de assimilar as mudanças de seu tempo, a educação tende a se transformar, para refletir as novas perspectivas que configuram o cenário atual.

Nesse contexto, redimenciona-se a discussão em torno da formação do professor. Conforme Mororó (2017) a discussão sobre a formação docente acentua-se frente às novas exigências sociais e econômicas, que tendem para um modelo educativo diferenciado. Como forma de atender as exigências atuais emergem novas propostas formativas docentes, uma dessas proposições, que vem abrindo espaço no cenário educacional brasileiro, por seu caráter flexível é a Educação a Distância - EaD. Vale lembrar sobre a importância em se "desenvolver políticas públicas educacionais que atendam aos professores, para além de suas necessidades formativas, absorvendo outras questões que influenciam na profissão e na identidade desses profissionais"(JARDILINO; SAMPAIO, 2019, p. 185).

É importante assinalar que a $\mathrm{EaD}$ da qual se fala hoje é diferente nas suas características e objetivos da EaD no início de sua constituição. Vivenciamos atualmente, a geração de classes virtuais com base na internet que possibilita a integração de diversas mídias (texto, áudio, imagem, vídeo) em uma única plataforma de comunicação. Essa integração de mídias possibilita a ampliação da interatividade entre os distintos participantes do processo educativo, ou seja, entre professores, alunos, administração e pessoal de apoio.

Um dos grandes diferenciais que a atual tecnologia digital oferece à EaD é a maior possibilidade de interação entre os agentes que participam do processo educacional. Este é um dos fatores que possibilitou o grande avanço e expansão apresentado pela EaD nos

Rev. Pemo, Fortaleza, v. 2, n. 1, p. 1-15, 2020

DOI: https://doi.org/10.47149/pemo.v2i1.3632

https://revistas.uece.br/index.php/revpemo

ISSN: 2675-519X

(c) (i) Esta obra está licenciada com uma Licença Creative Commons

Atribuição 4.0 Internacional. 
últimos tempos. Em um sistema de $\mathrm{EaD}$, todos os envolvidos no processo educativo são responsáveis pela aprendizagem. O papel e as tarefas do professor em EaD diferem das do ensino convencional, pois o "uso mais intenso dos meios de comunicação e informação torna o ensino mais complexo e exige a segmentação do ato de ensinar em múltiplas tarefas, sendo esta segmentação a característica principal do ensino à distância"(BELLONI, 2006, p. 79).

Nessa perspectiva, Belloni (2006, p.84) agrupa as funções docentes em três grandes grupos, a saber: concepção e realização do curso e materiais; o planejamento e organização da distribuição de materiais e da administração acadêmica (matrícula e avaliação); e o último, responsável pelo acompanhamento do estudante durante o processo de aprendizagem (tutoria, aconselhamento e avaliação. As discussões de Belloni (2006) sobre as funções do trabalho docente em EaD são fundamentais para que possamos elaborar um modelo conceitual de docência, inserido em uma base teóricoconceitual, que possa explicitar a concepção de como o professor deve assumir e agir sobre seu trabalho na prática da EaD (BEGO, 2016).

$\mathrm{O}$ estudante de $\mathrm{EaD}$, ao longo do processo de aprendizagem, tem contato com professores distintos em cada disciplina (autor/formador/especialista no conteúdo, tutor, especialista em $\mathrm{EaD}$ ), que o orientam sobre o mesmo conteúdo. Nesse caso, o aluno tem, através de diferentes meios e instâncias, contato com diferentes sujeitos que buscam colaborar com sua aprendizagem. Em função da experiência educacional tradicional em que existe a figura de apenas um professor responsável por uma disciplina ou conjunto de disciplinas, isso pode, em um primeiro momento, causar confusão tanto para docentes como para os estudantes. Para que haja organização sistêmica em cursos à distância, faz-se necessária a compreensão, por parte de todos os envolvidos, dos papéis que thes competem.

As definições dos diferentes papéis do professor na EaD podem variar de acordo com a instituição que desenvolve o projeto. "Não há um modelo único de educação à distância. Os programas podem apresentar diferentes desenhos e múltiplas combinações

Rev. Pemo, Fortaleza, v. 2, n. 1, p. 1-15, 2020

DOI: https://doi.org/10.47149/pemo.v2i1.3632

https://revistas.uece.br/index.php/revpemo ISSN: 2675-519X 
de linguagens e recursos educacionais e tecnológicos". (BRASIL, 2007). Segundo os Referenciais de Qualidade para Educação Superior a Distância - RQESD (BRASIL, 2007), a equipe responsável pelo processo formativo deve ser "multidisciplinar com funções de planejamento, implementação e gestão dos cursos a distância [...] docentes, tutores, pessoal técnico- administrativo (BRASIL, 2007, p. 19). O documento ressalta a importância da qualificação para esse corpo técnico-docente.

Este artigo tem como objetivo discutir sobre a identidade docente no exercício da tutoria em Educação a Distância. A metodologia foi de cunho teórico, fundamentada nas leituras de Alves, Simão e Leitinho (2018), Mororó (2017), Bego (2016), Belloni(2006), Gonzalez (2005), Mattar (2012), Bentes (2009). Também realizamos uma pesquisa documental com base em editais de seleção de tutores de três instituições públicas de Fortaleza que mantêm convênio dom a Universidade Aberta do Brasil.

O texto perpassa pelos papéis desempenhados pelo docente na $\mathrm{EaD}$; em seguida pela discussão em relação à identidade docente do tutor, e por fim, as conclusões.

\section{Os papéis desempenhados pelo docente na EaD}

Para analisar a interação dos diferentes papéis do professor nos cursos de graduação a distância, vamos utilizar as categorias propostas pela Secretaria de Educação a Distância (SEED) do Ministério da Educação, adotadas pela maioria das universidades públicas que trabalham com $\mathrm{EaD}$ e mantêm convênio com o Sistema UAB.

Aos docentes responsáveis por ministrar aulas presenciais (professor formador) ou elaborar material didático-pedagógico (professor conteudista), ao contrário do que possa parecer, são requisitados competências de mediação, além da capacidade de apreender, o motivo da sua prática pedagógica (MORORÓ,2017). Eles devem ser capazes, ainda, de elaborar material didático em uma linguagem específica para a $\mathrm{EaD}$ (professor conteudista); ser capaz de conseguir problematizar em curto espaço de tempo

Rev. Pemo, Fortaleza, v. 2, n. 1, p. 1-15, 2020

DOI: https://doi.org/10.47149/pemo.v2i1.3632

https://revistas.uece.br/index.php/revpemo

ISSN: 2675-519X 
os conteúdos propostos para a disciplina dos cursos (professor formador). A esses professores compete:

estabelecer os fundamentos teóricos do projeto; selecionar e preparar todo o conteúdo curricular articulado a procedimentos e atividades pedagógicas; identificar os objetivos referentes a competências cognitivas, habilidades e atitudes; definir bibliografia, videografia, iconografia, audiografia, tanto básicas quanto complementares; elaborar o material didático para programas a distância; realizar a gestão acadêmica do processo de ensinoaprendizagem, em particular motivar, orientar, acompanhar e avaliar os estudantes; avaliar-se continuamente como profissional participante do coletivo de um projeto de ensino superior a distância. (BRASIL, 2007, p. 20).

Ainda é importante ressaltar que todas as competências acima especificadas originam-se a partir das relações sociais estabelecidas pelos docentes durante o seu processo de desenvolvimento pessoal e profissional. Não se trata de algo intrínseco à sua natureza, mas sim de uma construção social (MORORÓ, 2017).

No que se refere ao acompanhamento dos alunos, encontramos a figura do tutor e para este profissional distinguem-se dois papéis: tutor presencial e tutor a distância. "O tutor deve ser compreendido como um dos sujeitos que participa ativamente da prática pedagógica. Suas atividades desenvolvidas a distância e/ou presencialmente devem contribuir para o desenvolvimento dos processos de ensino e de aprendizagem e para o acompanhamento e avaliação do projeto pedagógico" (BRASIL, 2007, p. 21).

O tutor presencial é a figura mais próxima do estudante, é o profissional que atende o aluno diretamente no polo, orientando-o na execução de suas atividades, auxiliando-o na organização do seu tempo e dos seus estudos. Uma das atribuições do tutor é tirar as dúvidas dos alunos em relação aos conteúdos apresentados; entratanto, dependendo da disciplina ou do conteúdo, essa tarefa poderá não ser desempenhada com sucesso.

O tutor a distância é o responsável pela mediação e pelo acompanhamento do aluno, oferecendo suporte em relação ao conteúdo ministrado na disciplina ou no curso. "A principal atribuição deste profissional é o esclarecimento de dúvidas através de fóruns de discussão pela Internet, pelo telefone, participação em videoconferências, entre outros"

Rev. Pemo, Fortaleza, v. 2, n. 1, p. 1-15, 2020

DOI: https://doi.org/10.47149/pemo.v2i1.3632

https://revistas.uece.br/index.php/revpemo

ISSN: 2675-519X

cC) (i) Esta obra está licenciada com uma Licença Creative Commons

Atribuição 4.0 Internacional. 
(BRASIL, 2007, p. 21). A esse profissional compete também promover espaços de construção coletiva, selecionar material e enviar material de apoio aos conteúdos estudados. Nesse sentido, compreendemos que a tutoria tem como "finalidade de melhorar a interação pedagógica entre tutores e tutorandos, extremamente necessária para orientar e apoiar os processos de ensino e de aprendizagem no ensino superior (ALVES, SIMÃO, LEITINHO, 2018, p.46). Os professores tutores desempenham um papel de fundamental importância no processo educacional de cursos superiores a distância. Em todos os estudos sobre EaD é consenso a importância do papel da tutoria no sucesso da aprendizagem e na manutenção dos alunos nos cursos (BELLONI, 2006). No entanto, convém indagarmos: porque a distinção entre professor e tutor? Porque o tutor em muitos programas de EaD não são considerados professores? Qual o significado de tutor?

Em função desses questionamentos nos propomos a discutir a identidade dos tutores nos ambientes de EaD. Tomamos como base para nossa reflexão as atribuições conferidas aos tutores, através dos editais de seleção, da Universidade Estadual do Ceará - UECE, Universidade Federal do Ceará - UFC e Instituto Federal de Educação, Ciência e Tecnologia do Ceará - IFCE, instituições públicas que oferecem cursos na modalidade a distância no estado do Ceará, por meio de convênio com o Sistema UAB.

\section{0 tutor é ou não um professor?}

Ao buscarmos a definição para tutor, encontramos no dicionário da língua portuguesa a seguinte: "indivíduo legalmente encarregado de tutelar alguém; protetor". (FERREIRA, 2001, p. 553). Se aplicássemos essa definição à educação, tomaríamos por tutor aquele que tem a função de tutelar, acompanhar a aprendizagem do estudante. Neste caso, a ele competiria apenas verificar se o aluno está aprendendo ou não, se está exercendo seu papel de estudante de forma adequada, orientando-o e estimulando-o quando necessário. Sá (1998) nos remonta ao século XV para explicar a origem da tutoria

Rev. Pemo, Fortaleza, v. 2, n. 1, p. 1-15, 2020

DOI: https://doi.org/10.47149/pemo.v2i1.3632

https://revistas.uece.br/index.php/revpemo ISSN: 2675-519X 
como método no qual o tutor exercia um papel de "acompanhante" do estudante, com o intuito de garantir que a estes fossem incutidas a fé e a conduta moral. Cinco séculos depois, o tutor assumiu a responsabilidade de orientar e acompanhar os trabalhos universitários, mantendo ainda o caráter de "orientador da aprendizagem".

Nas experiências iniciais de $\mathrm{EaD}$, por correspondência, o ensino era inspirado no modelo fordista de divisão de tarefas e de um planejamento normativo tradicional. Permanecia ainda a visão do tutor como mero "acompanhante" no processo ensinoaprendizagem. Neste modelo, o aluno aprendia por meio do estudo dos módulos e o tutor exercia uma função secundária (BELLONI, 2006). Vale lembrar que este modelo de EaD era baseado na teoria de aprendizagem associacionista, que considera a aprendizagem como mudança de comportamento e que portanto a ênfase era dada aos recursos e não ao professor.

Na perspectiva tradicional da educação a distância, era comum sustentar a ideia de que o tutor dirigia, orientava, acompanhava, mas não ensinava, pois quem ensinava era o material. Esse pensamento refletia a concepção de ensino como sinônimo de transmitir informação. A constituição da sociedade contemporânea, o surgimento de novas concepções pedagógicas de ensino e aprendizagem, os avanços tecnológicos e as possibilidades de interação nos programas a distância, sobretudo com o uso da internet, exigem do tutor novas competências e habilidades que ultrapassam essa visão tradicional de seu papel (ALMEIDA, 2002; BELLONI, 2006).

Segundo Aretio (2001), não existe um consenso entre autores e instituições quanto à denominação do docente que atua na $\mathrm{EaD}$, pois esta modalidade está relacionada com as funções exercidas nos diferentes modelos de EaD. Reconhece-se, no entanto, que o termo mais usado é tutor.O mesmo autor sustenta, ainda, que o sucesso das instituições educativas dependem em grande parte da formação, capacidade e atitude de seus docentes e que na $\mathrm{EaD}$ a docência não é direta: ela se utiliza de meios técnicos para possibilitar a comunicação, a qual é exercida por um professor atípico que é o tutor.

Rev. Pemo, Fortaleza, v. 2, n. 1, p. 1-15, 2020

DOI: https://doi.org/10.47149/pemo.v2i1.3632

https://revistas.uece.br/index.php/revpemo ISSN: 2675-519X 
Do exposto até aqui, vê-se que a palavra tutor, atualmente, está sendo designada ao docente que interage com o estudante virtualmente e que, por sua origem, é dicotomizada em ser professor ou não ser professor. Alguns autores consideram que é necessário a superação do termo tutor com a finalidade de definir a função docente na EAD (MATTAR, 2012). No modelo atual de se fazer EaD, "o papel do tutor extrapola os limites conceituais, impostos na sua nomenclatura, já que ele, em sua missão precípua, é educador como os demais envolvidos no processo" (GONZALEZ, 2005, p. 80).

Ademais, conforme Bego (2016), o modo como se concebe o papel docente influencia diretamente na organização do trabalho educativo como no próprio trabalho desenvolvido pelo professor. O pressuposto teórico-conceituais referente ao profissional repercute, também, na forma como ele é reconhecido.

Não nos restam dúvidas de que o tutor exerce, também, a função docente, e por esse motivo empregaremos o termo tutor com a mesma significação da terminologia encontrada em alguns autores (BELLONI, 2006; BENTES, 2009, BRUNO E LENGRUBER, 2009): professor- tutor. Cabe ainda lembrarmos que na $\mathrm{EaD}$ as funções docentes são separadas e fazem parte de um processo de planejamento e execução de divisão de tempo e espaço, tornando difícil a identificação de quem é o professor, uma vez que a EaD se constitui de um processo complexo que inclui muitas pessoas (BELLONI, 2006). Sendo assim, a docência na EaD não está centrada nas mãos de uma única pessoa, mas de um grupo de docentes no qual está inserido o professor-tutor.

Embora no modelo UAB de educação a distância não se reconheça o tutor como docente, observamos que ao tutor, de uma maneira geral, são requisitados conhecimentos e habilidades nesses ambientes de EaD que ultrapassam a perspectiva de mero "motivador". Consultamos os editais de seleção para tutor a distância das três universidades públicas de Fortaleza que mantêm convênio com a UAB e encontramos, entre outras, as seguintes atribuições exigidas ao tutor:

Rev. Pemo, Fortaleza, v. 2, n. 1, p. 1-15, 2020

DOI: https://doi.org/10.47149/pemo.v2i1.3632

https://revistas.uece.br/index.php/revpemo

ISSN: 2675-519X

(c) (i) Esta obra está licenciada com uma Licença Creative Commons

Atribuição 4.0 Internacional. 
PRÁTICAS EDUCATIVAS, MEMÓRIAS E ORALIDADES

Rev. Pemo - Revista do PEMO

O tutor a distância é responsável por fazer o acompanhamento pedagógico dos estudantes durante toda a disciplina, seja a distância, por meio do ambiente virtual, seja por ocasião dos encontros presenciais. São consideradas atribuições do tutor a distância: [...]

Conhecer, detalhadamente, os materiais didáticos da disciplina, procedimentos e recursos tecnológicos de apoio às atividades;

Deslocar-se até os polos para ministrar aulas por ocasião dos encontros presenciais;

Executar procedimentos de avaliação formativa e somativa em todas as atividades desenvolvidas pelos estudantes; [...] (UFC, 2010, p. 1-2) ${ }^{1}$

São consideradas as seguintes atribuições para Tutor (a) a Distância: [...] Conhecer detalhadamente os materiais, procedimentos e recursos tecnológicos presentes na disciplina;

Promover a sistematização e aprofundamento dos conteúdos veiculados através de comentários, esclarecimentos de dúvidas, explicitação de conceitos, respostas a questionamentos e solução de problemas;

Disponibilizar e fornecer informações, acompanhar e orientar as atividades propostas das disciplinas e os trabalhos realizados, esclarecendo dúvidas e respondendo com presteza os e-mails recebidos dos alunos;

Analisar o desempenho dos alunos e propor procedimentos que melhorem o seu rendimento, quando necessário; [...] (UECE, 2010, p. 2-3)²

Atribuições do tutor a distância: [...]

Acompanhar o desenvolvimento teórico-metodológico do curso;

Atender e orientar os alunos nas questões teórico metodológicas do curso;

Acompanhar o trabalho dos alunos, orientando, dirimindo as dúvidas e favorecendo a discussão;

Responder aos alunos no máximo em 48 horas. Realizar correção dos trabalhos acadêmicos, em no máximo 7 dias, além dos trabalhos de recuperação paralela e exames presenciais dos alunos;

Orientar os encontros presenciais e as práticas pedagógicas a serem realizados nos pólos;

Interagir com os tutores presenciais, auxiliando-os em suas dúvidas;

[...] (IFCE, 2010, p. 2) ${ }^{3}$

Pela leitura dos editais, podemos observar que ao tutor são exigidas competências que o docente, como mediador pedagógico, deve possuir, tais como: desenvolvimento de atividades conjuntas com os alunos com o intuito de favorecer-Ihes a aprendizagem; domínio do conteúdo; mediação pedagógica dos conteúdos. Além disso,

\footnotetext{
${ }^{1}$ Disponível em http://www.virtual.ufc.br/editais/01

2 Disponível em www.ead.uece.br.

${ }^{3}$ Disponível em www.ifce.edu. br
}

Rev. Pemo, Fortaleza, v. 2, n. 1, p. 1-15, 2020

DOI: https://doi.org/10.47149/pemo.v2i1.3632

https://revistas.uece.br/index.php/revpemo

ISSN: 2675-519X

cc) (i) Esta obra está licenciada com uma Licença Creative Commons

Atribuição 4.0 Internacional. 
a esse profissional também é exigido domínio técnico-pedagógico dos recursos utilizados no curso.

No Projeto Político Pedagógico do curso de Pedagogia da UAB/UECE na seção Administração, gerência e operacionalização do sistema a distância, há a descrição dos profissionais envolvidos no curso e suas respectivas atribuições, e o tutor a distância é assim definido: "tutor a distância é o professor designado para acompanhar o aluno num processo dialógico, propiciando-lhe um atendimento personalizado capaz de satisfazer suas necessidades de formação e suas expectativas pessoais sobre o programa." (UECE, 2008, p. 16). Essa definição é reforçada no módulo introdutório, sobre EaD, do curso de Pedagogia da UAB/UECE. No capítulo intitulado: Estrutura e Funcionamento da EAD no Curso de Pedagogia da UECE, que expressa a operacionalização pedagógica e administrativa do curso, o tutor a distância é assim descrito: "professor orientador é o docente designado para acompanhar [...]" (OLIVEIRA et al., 2010, p. 53, grifo nosso).

Somos levados a refletir sobre quais os motivos de, em alguns programas de EaD, inclusive no modelo UAB, ser negado ao tutor o "título" de professor. Podemos identificar como possíveis respostas a esse questionamento, além da visão de educação, as de ordem política e econômica.

A perspectiva do professor como mediador encontra suporte na teoria da aprendizagem sócio-interacionista. Para Vygotsky (1987), é a aprendizagem que embasa o desenvolvimento humano e não o contrário. A atividade instrumental e concreta, através da cooperação e interação social, induz a sedimentação dos processos mentais superiores. A zona de atuação da instrução é a região denominada zona de desenvolvimento proximal, que se constitui na distância entre o nível de desenvolvimento real, atual e o nível de desenvolvimento potencial (resolução de questões sob orientação de pessoas mais capazes e que já dominam esse nível de conhecimento).

Vê-se, então, que a aprendizagem na perspectiva interacionista não equivale a uma recepção passiva do conhecimento; mas tem no ensino a tarefa de potencializar e favorecer a formação de estruturas cognitivas. E é nesta perspectiva que inserimos o tutor

Rev. Pemo, Fortaleza, v. 2, n. 1, p. 1-15, 2020

DOI: https://doi.org/10.47149/pemo.v2i1.3632

https://revistas.uece.br/index.php/revpemo ISSN: 2675-519X 
como exercendo a função docente nos cursos de EaD; uma vez que neste contexto, o docente, como mediador pedagógico, deve possuir habilidades que estão presentes na tutoria. Algumas capacidades, tais como orientar a aprendizagem, motivar o aluno, conhecer as ferramentas tecnológicas, ser aberto a críticas, entre outras, são essenciais ao bom desempenho de um tutor em EaD. De acordo com Bentes (2009, p.167),

\begin{abstract}
o professor tutor assume características inerentes à sua função para trabalhar a EaD; deve saber lidar com os ritmos individuais diferentes de cada aluno, apropriar-se de novas TICs, dominar técnicas e instrumentos de avaliação, ter habilidades de investigação, utilizar novos esquemas mentais para criar uma nova cultura indagadora e plena em procedimentos de criatividade e ter disponibilidade para intervir a qualquer momento.
\end{abstract}

Percebe-se que o perfil do tutor de um curso a distância requer algumas características que estão além do domínio dos conteúdos e dos meios técnicos. Essas características referem-se a relacionamento interpessoal, concepção de educação de cada indivíduo e capacidade de estabelecer relações de afetividade e empatia a distância. Não basta apenas um discurso motivador e uma proposta de trabalho enfocando a construção do conhecimento de forma conjunta com o aluno. É fundamental que esse professor adquira ou desenvolva habilidades de relacionamento interpessoal que valorize um processo de formação flexível, com abertura para o diálogo e negociação constantes durante a aprendizagem.

Refletir sobre a prática pedagógica do professor-tutor significa perceber esse profissional sob o ponto de vista do exercício da docência. Sobre este aspecto, os problemas enfrentados na formação docente são muitos, cada vez mais os professores se encontram menos preparados para enfrentar as situações cotidianas da sua profissão, pois ela é muito complexa (VASCONCELLOS; BERNARDO, 2016). Aretio (2002) destaca que, apesar de uma variedade de estudos que descrevem qualidades de tutores em um curso de EaD, quatro qualidades principais parecem se repetir. São elas: cordialidade, capacidade de aceitação, honradez e empatia. A essas quatro qualidades, o autor acrescenta a capacidade de escutar e ler.

Rev. Pemo, Fortaleza, v. 2, n. 1, p. 1-15, 2020

DOI: https://doi.org/10.47149/pemo.v2i1.3632

https://revistas.uece.br/index.php/revpemo

ISSN: 2675-519X 
Convém lembrarmos, todavia, que as competências necessárias a uma docente para atuar na EaD, seja ele professor formador, tutor ou autor, entram em contraste com a formação que os profissionais da educação recebem, principalmente porque vivenciamos uma cultura de presencialidade no ensino e, para a $\mathrm{EaD}$, se faz necessário criar uma nova forma de pensar e elaborar os processos de aprendizagem. A formação de professores para atuar nessa área deve estar embasada em um novo paradigma de educação, atualmente, a formação docente não pode mais se limitar a formar para 0 ensino presencial e sem uso de TICs, mas deve considerar essas competências para uma formação plena. A formação do educador, tanto para o ensino presencial como para $\mathrm{EaD}$, perpassa três dimensões intimamente imbricadas umas às outras: dimensão pedagógica, relativa às concepções epistemológicas; dimensão didática, referente à formação específica do professor em uma das áreas do conhecimento; e dimensão tecnológica, abrangendo as relações entre tecnologia e educação, na utilização proficiente dos meios disponíveis, na avaliação e seleção de vídeos, softwares, tecnologias digitais e outros materiais técnico-educacionais, bem como na elaboração de estratégias de uso desses meios (BELLONI, 2006).

Como a EaD é uma modalidade de ensino eminentemente mediada, requer formação docente e estratégicas didático-pedagógicas específicas. Na formação específica para atuar na $\mathrm{EaD}$, é indispensável abordar os recursos tecnológicos nela empregados e a sua forma de organização.

Os cursos de formação de professores devem, portanto, considerar que os futuros professores precisam estar preparados para lidar com situações de mediação pedagógica, tanto no ensino presencial como a distância. Assim sendo, faz-se necessário uma formação que contemple esses aspectos como meio de contribuir para atuação dos docentes nos distintos espaços educativos.

\section{Considerações finais}

Rev. Pemo, Fortaleza, v. 2, n. 1, p. 1-15, 2020

DOI: https://doi.org/10.47149/pemo.v2i1.3632

https://revistas.uece.br/index.php/revpemo

ISSN: 2675-519X

(c) (i) Esta obra está licenciada com uma Licença Creative Commons

Atribuição 4.0 Internacional. 
Diante do exposto, concluímos que a tutoria é inerente à função de educar realizada por cada professor, o tutor realiza inúmeras atividades próprias da docência, como pudemos perceber na literatura e nos documentos estudados ele deve ser capaz de desenvolver atividades conjuntas com os alunos com o intuito de favorecer-Ihes a aprendizagem e com outros professores; deve ter o domínio do conteúdo; mediação pedagógica dos conteúdos, bem como a seleção de materiais e planejamento e de atividades, dentre outras.

O tutor contribui para desenvolvimento integrado do indivíduo, em seus diferentes campos: pessoal, escolar, profissional. Por isso, é uma função do ensino à distância que não se restringe apenas à transmissão de conhecimentos, ser tutor de um curso a distância requer características que estão além do domínio dos conteúdos e dos meios técnicos.

\section{Referências}

ALMEIDA, Maria Elizabeth Bianconcini de. Incorporação da tecnologia de informação na escola: vencendo desafios, articulando saberes, tecendo rede. In. MORAES, Maria Cândida (org.). Educação a distância: fundamentos e práticas. São Paulo: UNICAMP/NIED, 2002.

ALVES, Francione Charapa; SIMÃO, Ana Margarida Veiga; LEITINHO, Meirecele Calíope. Ação tutorial no ensino superior: experiência com alunos Maiores de $23 \mathrm{em}$ uma instituição pública de Portugal. Educação \& Formação, v. 3, n. 7, p. 44-65, 2018. Disponível em: https://revistas.uece.br/index.php/redufor/article/view/171. Acesso em: 15 abr. 2020.

ARETIO, Lorenzo Garcia. La educacion a distancia: De la teoría a la práctica. $2^{\underline{a}}$ ed. Barcelona: Editora Ariel, 2002.

BEGO, A. Políticas públicas e formação de professores sob a perspectiva da racionalidade comunicativa: da ingerência tecnocrata à construção da autonomia profissional. Educação \& Formação, v. 1, n. 2, p. 3-24, 2016. Disponível em: https://revistas.uece.br/index.php/redufor/article/view/98. Acesso em: $30 \mathrm{abr}$. 2020.

Rev. Pemo, Fortaleza, v. 2, n. 1, p. 1-15, 2020

DOI: https://doi.org/10.47149/pemo.v2i1.3632

https://revistas.uece.br/index.php/revpemo ISSN: 2675-519X 
BELLONI, Maria Luiza. Educação a distância. 4ª Ed. Campinas: Autores Associados. 2006.

BENTES, Roberto de Fino. A avaliação do tutor. In. LITTO, Frederic; FORMIGA, Marco. Educação a Distância: o estado da arte. São Paulo, Pearson, 2009.

BRASIL. Referenciais de Qualidade para Educação Superior a Distância.

Brasília, 2007. Disponível em: http://portal.mec.gov.br/par/193-secretarias112877938/seed-educacao-a-distancia-96734370/12777-referenciais-de-qualidadepara-ead. Acesso em: 21 abr. 2020.

FERREIRA, Aurélio Buarque de Holanda, Miniaurélio Século XXI: o minidicionário da língua portuguesa. Rio de Janeiro: Nova Fronteira, 2001.

FORTAleZA. Projeto Político Pedagógico do Curso de Licenciatura em Pedagogia na Modalidade a Distância. Fortaleza: UECE, 2008.

GONZALEZ, Mathias. Fundamentos da tutoria em Educação a Distância. São Paulo: Editora Avercamp, 2005.

MATTAR, João. Tutoria e interação em educação a distância. São Paulo: Cencage Learning, 2012.

MORORÓ, L. A influência da formação continuada na prática docente. Educação \& Formação, v. 2, n. 1, p. 36-51, 2017. Disponível em:

https://revistas.uece.br/index.php/redufor/article/view/122. Acesso em: 30 abr. 2020.

OLIVEIRA, Edite Colares et al. Introdução à Educação a Distância. Fortaleza:

Sistema UAB/UECE, 2010.

SÁ, Iranita M. A. Educação a Distância: Processo Contínuo de Inclusão Social. Fortaleza: C.E.C., 1998.

VYGOTSKY, Lev. S. Pensamento e linguagem. São Paulo: Martins Fontes, 1987.

VASCONCELLOS, Katia Regina Teixeira; BERNARDO, Elisangela da Silva. Profissionalização docente: reflexões e perspectivas no brasil. Educação \& Formação, Fortaleza, v. 1, n. 2, p. 208-222, 2016. Disponível em:

https://revistas.uece.br/index.php/redufor/article/view/109. Acesso em: 20 abr. 2020.

Rev. Pemo, Fortaleza, v. 2, n. 1, p. 1-15, 2020

DOI: https://doi.org/10.47149/pemo.v2i1.3632

https://revistas.uece.br/index.php/revpemo

ISSN: 2675-519X

(c) () Esta obra está licenciada com uma Licença Creative Commons

Atribuição 4.0 Internacional. 
JARDILINO, José Rubens; SAMPAIO, Ana Maria Mendes. Desenvolvimento profissional docente: reflexões sobre política pública de formação de professores. Educação \& formação, v. 4, n. 1, p. 180-194, 2019. Disponível em: https://revistas.uece.br/index.php/redufor/article/view/848. Acesso em: 20 abr. 2020.

\begin{tabular}{l} 
'Antonio Cavalcante Filho, ORCID: https://orcid.org/0000-0003-0017-3174 \\
Faculdade de Desenvolvimento das Américas - FADAM \\
Doutor em Educação (UECE- 2018). Mestre em Educação (UECE -2013) e Graduado em \\
Pedagogia (UECE -2002). Supervisor Escolar da Prefeitura Municipal de Fortaleza - PMF e \\
professor do curso de Pedagogia da Faculdade de Desenvolvimento das Américas - FADAM. \\
Contribuição de autoria:Administração do projeto. \\
Lattes: \\
Ettp://lattes.cnpq.br/5209001824374968 \\
\hline
\end{tabular}

"Viviani Maria Barbosa Sales, ORCID: https://orcid.org/0000-0002-7927-4711
Faculdade de Desenvolvimento das Américas - FADAM.
Doutora em Educação (UECE- 2017). Mestra em Educação (UECE -2011). Especialista em Mídias
na Educação (UFC-2012) e Graduada em Pedagogia (UECE -2002). Técnica da Célula de
Formação da Prefeitura Municipal de Fortaleza - PMF e professora do curso de Pedagogia da
Faculdade de Desenvolvimento das Américas - FADAM
Contribuição de autoria: Escrita - Primeira Redação.
Lattes:
E-mailttp://lattes.cnpq.br/3190439742049436

iii Francione Charapa Alves, ORCID: http://orcid.org/0000-0002-8405-8773
Universidade Federal do Cariri-UFCA/ Programa de Mestrado Profissional em Educação da
Universidade Regional do Cariri - PMPEDU/URCA.
Pós- doutora em Educação (UECE- 2017). Doutora em Educação (UFC-2016). Doutorado
Sanduíche (UL-Lisboa -2016). Mestre em Educação (UECE-2011). Professora Adjunta da
Universidade Federal do Cariri- UFCA. Colaboradora do Programa de Mestrado Profissional em
Educação da Universidade Regional do Cariri-URCA.
Contribuição de autoria: análise formal.
Lattes: $\frac{\text { http://lattes.cnpq.br/3924678282455249 }}{\text { E-mail: francione.alves@ufca.edu.br }}$

Editora responsável: Cristine Brandenburg

\section{Como citar este artigo (ABNT):}

CAVALCANTE FILHO, Antonio; SALES, Viviani Maria Barbosa; ALVES, Francione Charapa. Tutoria e identidade docente na educação a distância. Rev. Pemo, Fortaleza, v. 2, n. 1, p. 1-15, 2020. Disponível em: https://revistas.uece.br/index.php/revpemo/article/view/3632

Rev. Pemo, Fortaleza, v. 2, n. 1, p. 1-15, 2020 DOI: https://doi.org/10.47149/pemo.v2i1.3632 https://revistas.uece.br/index.php/revpemo ISSN: 2675-519X 